\title{
Knowledge, attitude and practice of infant feeding in the first 6 months among HIV-positive mothers at the Queen Mamohato Memorial hospital clinics, Maseru, Lesotho
}

\begin{tabular}{|c|c|}
\hline \multicolumn{2}{|c|}{$\begin{array}{l}\text { Authors: } \\
\text { Stephen O. Olorunfemi }{ }^{1} \\
\text { Lilian Dudley }^{1}\end{array}$} \\
\hline \multicolumn{2}{|c|}{$\begin{array}{l}\text { Affiliations: } \\
\text { }{ }^{2} \text { Division of Community } \\
\text { Health, Faculty of Medicine } \\
\text { and Health Sciences, } \\
\text { Stellenbosch University, } \\
\text { South Africa }\end{array}$} \\
\hline \multicolumn{2}{|c|}{$\begin{array}{l}\text { Corresponding author: } \\
\text { Stephen Olorunfemi, } \\
\text { stevoo1964@yahoo.com }\end{array}$} \\
\hline \multicolumn{2}{|c|}{$\begin{array}{l}\text { Dates: } \\
\text { Received: } 16 \text { Feb. } 2016 \\
\text { Accepted: } 08 \text { Nov. } 2017 \\
\text { Published: } 17 \text { May } 2018\end{array}$} \\
\hline \multicolumn{2}{|c|}{$\begin{array}{l}\text { How to cite this article: } \\
\text { Olorunfemi SO, Dudley, L. } \\
\text { Knowledge, attitude and } \\
\text { practice of infant feeding in } \\
\text { the first } 6 \text { months among } \\
\text { HIV-positive mothers at the } \\
\text { Queen Mamohato Memorial } \\
\text { hospital clinics, Maseru, } \\
\text { Lesotho. Afr J Prm Health } \\
\text { Care Fam Med. 2018;10(1), } \\
\text { a1438. https://doi.org/ } \\
\text { 10.4102/phcfm.v10i1.1438 }\end{array}$} \\
\hline \multicolumn{2}{|c|}{$\begin{array}{l}\text { Copyright: } \\
\text { (c) 2018. The Authors. } \\
\text { Licensee: AOSIS. This work } \\
\text { is licensed under the } \\
\text { Creative Commons } \\
\text { Attribution License. }\end{array}$} \\
\hline \multicolumn{2}{|l|}{ Read online: } \\
\hline 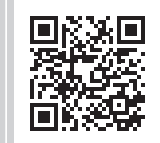 & $\begin{array}{l}\text { Scan this QR } \\
\text { code with your } \\
\text { smart phone or } \\
\text { mobile device } \\
\text { to read online. }\end{array}$ \\
\hline
\end{tabular}

Background: The balance between the risks of transmission of human immunodeficiency virus (HIV) through breastfeeding and its life-saving benefits complicates decisions about infant feeding among HIV-positive mothers in the first 6 months.

Objective: The aim of this study was to assess the knowledge, attitude and practice of infant feeding among HIV-positive mothers attending the prevention of mother-to-child transmission services in Maseru, Lesotho.

Method and setting: This observational cross-sectional study was done by collecting data from HIV-positive mothers attending the filter clinics of Queen Mamohato Memorial hospital in Maseru, Lesotho. HIV-positive mothers with infants below the age of 6 months attending the clinics at the time of the study were interviewed using a standardised questionnaire. We described the sociodemographic profile of the mothers, the information and education received on prevention of mother-to-child transmission (PMTCT) infant feeding options, the mothers' knowledge, attitudes and practices of infant feeding, and assessed risk factors for improved knowledge, attitudes and practices.

Results: The majority (96\%) of the 191 HIV-positive mothers who participated in the survey knew about the PMTCT programme and related breastfeeding services. Most of the participants chose to breastfeed (89\%), while only $8 \%$ formula-fed their infants. Knowledge received during the PMTCT programme was significantly associated with the decision to exclusively breastfeed their infants. Earlier infant feeding counselling and education was associated with more exclusively breastfeeding as compared to late infant feeding counselling $(p<0.001)$.

Conclusion: The study found that HIV-positive mothers attending health clinics in Maseru, Lesotho, had high knowledge, and appropriate attitudes and practices with respect to infant feeding; and that early counselling and education improved infant feeding methods among these mothers.

\section{Introduction}

The Joint United Nations Programme on HIV/AIDS (UNAIDS) reported in 2015 that there were an estimated 36.7 million people living with HIV globally, 1.8 million of whom were children. Of this population, 2.1 million were newly infected and 1.1 million died from the disease. ${ }^{1}$ Approximately 380000 of the 1.89 million population of Lesotho are infected with HIV, of whom 38000 were children between the age of $0-15$ years and 342000 were adults above the age of 15 years in $2014 .^{2}$ Of an estimated 55000 annual births in the country, approximately 15235 infants were born to HIV-infected mothers in $2014 .^{2}$

The prevention of mother-to-child transmission (PMTCT) of HIV programme was officially launched in Lesotho in February 2003, and it serves as an entry point for the prevention of HIV infection and care of HIV-infected women and their exposed infants. Currently there are 186 PMTCT sites, reflecting an increase in programme coverage from $16 \%$ in 2006 to $71 \%$ in 2009. This was made possible by the expanded training of health care providers, adoption of the provider-initiated testing approach, involvement of partners at implementation sites and the decentralisation of PMTCT services to health centre level in the entire country. PMTCT services are integrated into antenatal clinics (ANC) and all other maternal and child health $(\mathrm{MCH})$ services. ${ }^{3}$ Health care providers educate these mothers on the importance of exclusively breastfeeding in 
addition to providing antiretroviral treatment (ART), which is referred to as Option B plus. ${ }^{3}$ Because of the transmissibility of HIV from mother to child during breastfeeding, the prevention of HIV infection during this period depends on appropriate feeding practices. This period has proven to be crucial in controlling the spread of the virus from HIVpositive mothers to their infants. ${ }^{3}$

In Lesotho, the general population of mothers who exclusively breastfed their infants under 6 months has increased over the last decade, from $36 \%$ in 2004 to $67 \%$ in 2014. ${ }^{4}$ Exclusive breastfeeding (EBF) declines with infant age: $44 \%$ of infants aged $4-5$ months compared with $82 \%$ of infants aged $0-1$ month and $76 \%$ of infants aged $2-3$ months. ${ }^{4}$ Little research has been conducted in Lesotho to determine the prevalence of exclusive formula feeding (EFF) or mixed feeding (MF) in the population. The only study carried out among exposed infants in rural Lesotho in 2008 revealed that $76.7 \%$ of HIV-positive infants were exclusively breastfed, while $23.3 \%$ were exclusively formula-fed. The study did not report on $\mathrm{MF}^{5}$

In 1999, De Cock et al. estimated that between 5\% and 20\% of infants would become infected if breastfed beyond 18 months. ${ }^{6}$ A meta-analysis by the Breastfeeding and HIV International Transmission Study Group found that $42 \%$ of infant infections were attributed to breast milk. ${ }^{7}$ Kourtis et al. calculated that without any intervention, approximately 6\% of HIV-exposed infants would become infected via breastfeeding if they were exclusively breastfed for 6 months and rapidly weaned; $11 \%$ would become infected if they were mixed fed for 6 months, then rapidly weaned; and 15\% would become infected if they were breastfed for 2 years. ${ }^{8}$ In the absence of effective interventions to prevent transmission of HIV during pregnancy, delivery or breastfeeding among HIV-infected pregnant women, it is estimated that $35 \%$ of births will result in MTCT of HIV. ${ }^{6}$ It is estimated that $3 \%$ of all under-5 mortalities in low-income countries could be prevented through mothers who exclusively breastfeed their infants during the critical first 6 months of life. ${ }^{7}$ Exclusively breastfeeding therefore plays a critical role in the overall health of infants, and is a global health objective, given its importance in the reduction of morbidity and mortality among infants, particularly in low-income countries where safe water and sanitation are often absent. ${ }^{6}$ The predicament concerning feeding infants of HIV-positive mothers is how to balance the risk of HIV transmission through breastfeeding with the risk of death from other causes other than HIV such as pneumonia, diarrhoeal diseases and malnutrition among formula-fed infants. ${ }^{9}$

The Government of Lesotho has implemented several HIV prevention strategies, including educational campaigns, work-based HIV prevention initiatives, the targeting of highrisk groups and PMTCT. ${ }^{10}$ All HIV-infected mothers attending health facilities in Lesotho receive information to assist them decide how to feed their infants, and to select the infant feeding option (IFO) that is most suitable to their situation. HIV-infected mothers in the country are also provided with Option B plus that was introduced in April 2013. ${ }^{11}$
It recommends providing lifelong ART to all pregnant and breastfeeding women living with HIV regardless of cluster of differentiation four (CD4) count or World Health Organization (WHO) clinical stage. ART is maintained for life after delivery and after the completion of breastfeeding. ${ }^{1}$

The PMTCT programme in Lesotho has made some advances in the past few years by creating great awareness of MTCT around the country. ${ }^{1}$ This was done through innovative strategies such as integration of ART for HIV-positive pregnant and lactating women and their infants in accessing services at the $\mathrm{MCH}$ unit, and with the integrated outreach community services. The use of community health workers to provide HIV testing, counselling and adherence support has allowed for early diagnosis, treatment and monitoring in the country's remotest areas. ${ }^{1}$ Although the proportion of postnatal transmissions attributable to breastfeeding is not known exactly, it is likely to steadily decrease as the availability of prenatal and peripartum antiretroviral (ARV) prophylaxis continues to increase. ${ }^{10,11}$ Nevertheless, the successful reduction of MTCT remains dependent on adherence to EBF or replacement feeding (RF) of the baby for the first 6 months of life. ${ }^{12}$ The lack of appropriate knowledge, attitudes and practices (KAP) of infant feeding by HIVpositive mothers may therefore lead to an increase in MTCT of the virus. ${ }^{2}$

The following WHO or United Nations Children's Fund or UNAIDS definitions are used for describing feeding options: EBF is defined as giving only breast milk and prescribed medicine, but no water, other liquids or food to infants. Exclusive replacement feeding (ERF) is the process of feeding a child who is not receiving any breast milk with a diet that provides all the nutrients the infant needs. Exclusive formula feeding is defined as feeding an infant only with prepared formula instead of the breast milk. Mixed feeding is defined as giving other liquids or foods together with breast milk to infants under 6 months of age. ${ }^{10}$ Replacement feeding is the provision of suitable breast milk substitutes that provide the necessary nutrients instead of breast milk, and include commercial infant formula (IF) or homemodified animal milk. ${ }^{10}$

The 2014 Lesotho National ARV guidelines recommend EBF for the first 6 months of an infant's life, lifelong ARVs for the mother and Nevirapin (NVP) from birth to 6 weeks of the infant's life. ${ }^{2}$ However, it provides specific conditions under which RF (with commercial IF) can be given to an HIVexposed infant if the mother is on Option B plus. These include access to safe water and sanitation, a reliable supply of sufficient IF milk which the mother is able to prepare cleanly and frequently enough; the ability to exclusively give IF milk for the first 6 months, with full family support; and the ability to access health care that offers comprehensive child health services.

The above recommendations align with international recommendations for RF summarised as acceptable, feasible, affordable, sustainable and safe (AFASS). ${ }^{10}$ When AFASS 
criteria cannot be met, especially in a resource-challenged country with a high burden of HIV like Lesotho, HIV-positive mothers are advised to EBF and avoid MF the infants in the first 6 months. ${ }^{11,12}$

No previous studies have been conducted on the KAP of infant feeding among HIV-positive mothers in Lesotho. A South African study among 815 HIV-positive mothers attending postnatal clinics (mothers' mean age was 27.7 years) showed that $71 \%$ knew that HIV could be transmitted during pregnancy, $78.7 \%$ knew that it could be transmitted during delivery and $78 \%$ agreed that it could be transmitted by breastfeeding. Half (50.6\%) were EFF, 35.6\% EBF and 12.4\% reported MF. The study reported that $94.4 \%$ of women had received counselling on IFOs, although $14.7 \%$ did not receive counselling on IFOs within $72 \mathrm{~h}$ of delivery. Of the participants, $93 \%$ received information on the dangers of MF. ${ }^{13}$

A study in Kenya to assess the KAP with regard to infant feeding in the context of HIV showed that most of the respondents $(85.5 \%)$ knew about breastfeeding as a route of HIV transmission. Breastfeeding was the custom in the society, but exclusive breastfeeding was not practiced among HIV-positive mothers. Cow's milk, the main breast milk substitute, was reported as being given to infants as early as 2 weeks and was the most popular (93.5\%) IFO in the context of HIVand AIDS. ${ }^{14}$

In Uganda, a study on the knowledge of MTCT of HIV among women enrolled in the PMTCT programme showed that out of 198 women, $26 \%$ believed that transmission of the virus is inevitable. ${ }^{15}$ A similar study in Ghana among HIVpositive mothers with infants aged 0-12 months showed that 33 (83\%) out of the 40 HIV-positive mothers interviewed had received counselling on MTCT of HIV and WHO recommended feeding options during either antenatal care or postnatal services. Thirty-six participants (90\%) mentioned the IFOs to include EBF and ERF. The majority of participants correctly understood EBF and only $10 \%$ partially understood $\mathrm{ERF}^{16}$

Most of these studies demonstrated the major predictors of IFOs ranging from maternal attributes, mode of delivery and disclosure of HIV status to a spouse.

However, the most important factor was the knowledge acquired during the PMTCT programme. ${ }^{17}$ In addition, the information, education and counselling (IEC) provided to HIV-positive mothers during this period should include information about the risks and benefits of various IFOs and guidance in selecting the most suitable options for them and their infants.

Community views concerning the dangers of HIV transmission through breastfeeding and the discrimination associated with not breastfeeding make it difficult for HIVpositive mothers to initiate and maintain optimal infant feeding practices. ${ }^{18}$ Safe infant feeding in the context of HIV requires communication between parents and the whole family, as well as thorough, intensive community education, counselling and support. ${ }^{19}$

The aim of this study was therefore to determine the extent to which HIV-positive mothers attending PMTCT services in Lesotho complied with recommended infant feeding practices, and to identify factors that influenced their KAP. ${ }^{6}$

Self-reported maternal recall has been found to be a valid and reliable method of describing breastfeeding practices in cross-sectional studies, particularly for recall periods of less than 6 months. ${ }^{20}$ We therefore conducted a cross-sectional study of KAP of infant feeding of HIV-positive mothers with infants less than 6 months old.

\section{Methods \\ Study design and setting}

A cross-sectional study design was used to describe the infant feeding KAP of HIV-positive mothers registered at three primary health care facilities (Mabote, Qoaling and Likosi clinics) which refer patients to the Queen Mamohato Memorial hospital located in Maseru the capital city of Lesotho. The three clinics serve an estimated population of approximately 89000 in the city of Maseru, which has a total population of about 4 million. ${ }^{18,21}$

\section{Sampling and data collection}

Systematic sampling was employed to select HIV-positive mothers 18 years and older, with infants less than 6 months old, who visited and registered at the clinics during February and March 2015. Data collection was conducted using faceto-face interviews to complete a standardised questionnaire (Appendix 1) with each mother at the health facility. Mothers or infants with acute, life-threatening illness or neonatal deaths before 6 months were excluded from the study.

The desired sample size of 191 was estimated using Fisher's formula, with the assumption of $95 \%$ confidence level, a margin of error of $5 \%$ and a prevalence value of knowledge of infant feeding based on western Kenya of $85.5 \% .{ }^{21}$ The total number of questionnaires for the study was increased to 210 , with an addition of $10 \%(19)(191+19)$ to allow for incomplete or unreliable answers from the participants. Five participants provided incomplete or incorrect responses which were corrected immediately in the field, and 14 incomplete questionnaires were discarded.

\section{Data handling and analysis}

Three hospital nurses who were trained as research assistants conducted the interviews in the native language of the participants using a structured questionnaire which was adapted from an earlier WHO AIDS Questionnaire. ${ }^{22}$ A pilot study was conducted to pre-test the questionnaire with 15 HIV-positive mothers at the Mabote clinic. Each completed questionnaire was checked manually by the research assistants, and subsequently quality checked and captured 
into an Excel spreadsheet by the principal investigator (PI) at the end of each day. Inconsistent values were checked against the original questionnaire and corrected as necessary by the PI. The data were analysed using Stata version $13^{23}$ with the assistance of a statistician.

The analysis described the sociodemographic characteristics of participants, exposure to IEC on PMTCT and IFOs, and KAP of PMTCT and infant feeding. The results were organised in frequency counts, tables and graphs. With regard to KAP about breastfeeding in PMTCT, the number of correct responses by participants was categorised as either 'high' or 'low' knowledge.

Bivariate analysis and Fisher's exact test or Pearson's chisquared test were used to assess factors associated with the KAP of IFOs. A two-tailed probability level of $p<0.05$ was chosen as the level of statistical significance in the analysis.

Fisher's exact test or Pearson's chi-squared test was used to compare results between categorical data. Some groups were combined because of small numbers as follows:

- Completely satisfied or very satisfied or somewhat satisfied $=$ Satisfied

- $\quad$ Somewhat dissatisfied or very dissatisfied = Dissatisfied

- No and do not know = No.

TABLE 1a: Demographic characteristics HIV-positive mothers attending prevention of mother-to-child transmission clinics in Maseru, Lesotho, 2015.

Demographic variables

$N=191$

\section{Age (years)}

\section{8-25}

26-35

$>36$

125

Marital statu

Single

Married

Other'

Religion

Christian

Muslim

Traditional

Other

Education

Primary or less

Secondary

Higher

Employment

Government

Private

Self-employed

Unemployed

Student

Parity

Primigravida (1)

Low parity (2-3)

High parity ( $\geq 4$ )

$N$, number.

$\dagger$, other groups includes combined number of divorced, separated and widowed.

\section{Ethical considerations}

Ethical approval (Ref\#: S15/09/213) was obtained from the Health Research Ethics Review Committee of the Faculty of Medicine and Health Sciences, University of Stellenbosch, South Africa. Informed consent was obtained from all participants who agreed to be interviewed.

\section{Results \\ Demographic profile and factors associated with practising exclusively breastfeed among the participants}

Data were obtained from $191 \mathrm{HIV}$-positive mothers who had infants between the ages of 2 weeks and 6 months. The demographic profile of the respondents, including age, marital status, education, employment status and parity, is summarised in Table 1.

The majority of respondents $(189,99 \%)$ had their infant tested for HIV, of whom 187 (98\%) were HIV negative, while two (1\%) of the infants had not received the test report during the period of the study. The viral load level was not included in the study. Of the 191 mothers, only two had a caesarean section done at the main hospital, while all others had a normal vaginal delivery. Most $(134,70 \%)$ of the mothers confirmed that their partner was aware of their HIV status.

TABLE 1b: Information, education and communication (IEC) on mother-to-child transmission among HIV-positive mothers attending prevention of mother-tochild transmission clinics in Maseru, Lesotho, 2015.

\begin{tabular}{|c|c|c|}
\hline $\begin{array}{l}\text { Information, education and communication on } \\
\text { infant }(N=191) \text { feeding options }\end{array}$ & $n$ & $\%$ \\
\hline \multicolumn{3}{|l|}{ When IEC on IFO was provided } \\
\hline Never & 5 & 3 \\
\hline During pregnancy or immediate postpartum & 169 & 88 \\
\hline Weeks postpartum & 11 & 57 \\
\hline Months postpartum & 6 & 3 \\
\hline \multicolumn{3}{|l|}{ Nature of IEC on IFO } \\
\hline To breastfeed only & 25 & 13 \\
\hline To formula feed only & 15 & 26 \\
\hline To give both breastfeeding and formula & 0 & 0 \\
\hline $\begin{array}{l}\text { Counselled on both exclusive breastfeeding and } \\
\text { exclusive formula feeding and asked to make a } \\
\text { choice }\end{array}$ & 151 & 79 \\
\hline \multicolumn{3}{|l|}{ Satisfaction with IEC } \\
\hline Completely satisfied & 76 & 40 \\
\hline Very satisfied & 96 & 50 \\
\hline Somewhat satisfied & 15 & 8 \\
\hline Somewhat dissatisfied & 2 & 1 \\
\hline Very dissatisfied & 2 & 1 \\
\hline Completely dissatisfied & 0 & 0 \\
\hline \multicolumn{3}{|l|}{ Main source of IEC } \\
\hline Partner & 4 & 2 \\
\hline Mother & 63 & 32 \\
\hline Friends & 2 & 1 \\
\hline Nurse & 120 & 62 \\
\hline Community health worker & 2 & 1 \\
\hline \multicolumn{3}{|l|}{ IFO advised against } \\
\hline Exclusive breastfeeding & 0 & 0 \\
\hline Infant formula feed & 5 & 3 \\
\hline Mixed feeding & 166 & 87 \\
\hline Cow's milk & 20 & 10 \\
\hline
\end{tabular}

Cow's milk

20

10

IEC, Information, education and communication; IFOs, infant feeding options. 
TABLE 2: Knowledge, attitudes and practices in relation to infant feeding options among HIV-positive mothers attending prevention of mother-to-child transmission clinics in Maseru, Lesotho, 2015.

\begin{tabular}{|c|c|c|}
\hline Variable & $n$ & $\%$ \\
\hline \multicolumn{3}{|l|}{ A: Knowledge of MTCT and IFOs } \\
\hline \multicolumn{3}{|l|}{ Infant feeding options (IFOs) } \\
\hline Cow's milk & 19 & 10 \\
\hline Infant formula only & 29 & 15 \\
\hline Breastfeeding only & 152 & 79 \\
\hline \multicolumn{3}{|l|}{ Methods of reducing HIV in breast milk } \\
\hline $\begin{array}{l}\text { Stop breastfeeding as soon as feasible in the } \\
\text { first few months }\end{array}$ & 5 & 3 \\
\hline $\begin{array}{l}\text { Avoid mixed feeding or give only breast milk } \\
\text { or formula }\end{array}$ & 174 & 91 \\
\hline Heat treating milk & 50 & 26 \\
\hline Give antiretroviral to the mother and child & 175 & 92 \\
\hline \multicolumn{3}{|l|}{ IFO with highest HIV transmission } \\
\hline Exclusive breastfeeding & 3 & 16 \\
\hline $\begin{array}{l}\text { Mixed feeding (giving both breast milk and } \\
\text { formula) }\end{array}$ & 185 & 97 \\
\hline Do not know & 3 & 16 \\
\hline \multicolumn{3}{|l|}{ Mother aware of the benefit of EBF } \\
\hline Yes & 171 & 90 \\
\hline No & 20 & 10 \\
\hline \multicolumn{3}{|l|}{ B: Attitudes towards MTCT and IFOs } \\
\hline \multicolumn{3}{|l|}{ EBF sufficient for 6 months } \\
\hline Yes & 100 & 52 \\
\hline No & 91 & 48 \\
\hline \multicolumn{3}{|c|}{ Feel discriminated against in community about IFO } \\
\hline Yes & 185 & 97 \\
\hline No & 2 & 1 \\
\hline Don't know & 4 & 2 \\
\hline \multicolumn{3}{|l|}{ C: Infant feeding practices } \\
\hline \multicolumn{3}{|l|}{ Duration of EBF (months) } \\
\hline Less than 1 month & 0 & 0 \\
\hline $2-3$ months & 10 & 5 \\
\hline $4-5$ months & 167 & 87 \\
\hline Still breastfeeding & 14 & 7 \\
\hline Others & 0 & 0 \\
\hline \multicolumn{3}{|l|}{ Challenges with EFF } \\
\hline Expensive cost of purchasing formula milk & 16 & 8 \\
\hline Pressure from relatives to breastfeed & 160 & 84 \\
\hline No challenges & 15 & 8 \\
\hline \multicolumn{3}{|l|}{ Method of feeding used while formula feeding } \\
\hline Feeding bottle & 10 & 67 \\
\hline Cup and spoon & 3 & 20 \\
\hline Both feeding bottle and cup and spoon & 2 & 13 \\
\hline
\end{tabular}

MTCT, mother-to-child transmission; IFO, Infant feeding option; EBF, exclusive breastfeeding, $\mathrm{EFF}$, exclusive formula feeding.

Of the 191 respondents, 189 (99\%) were on ART, of whom 132 (69\%) started therapy during pregnancy, 38 (20\%) were on treatment before their pregnancy and $19(10 \%)$ started therapy after delivery. Only two (1\%) of the mothers were yet to start therapy. Other attributes of the mothers with respect to IEC like IFO on type of feeding to avoid are included in Table 1.

\section{Knowledge, attitude and practice of infant feeding option}

The various factors associated with KAP of HIV-positive in EBF their infants in the first six 6 months are displayed in Table 2.

The mothers' knowledge of MTCT through infant feeding was good. Most of the mothers $(152,80 \%)$ were aware of the two main IFOs (breastfeeding and IF), while only 39 (20\%) had knowledge of other feeding options. Ninety-four per cent of the mothers (179) were aware of the risk of transmitting HIV to their infants during breastfeeding.

More than half $(100,52 \%)$ of the mothers agreed that breast milk alone was sufficient for the infant in the first 6 months, while $91(48 \%)$ felt that this was not enough for proper growth.

The mothers' knowledge of methods of HIV transmission during breastfeeding was categorised as 'high' if the participant responded correctly to two or more of the questions, or 'low' if the participant responded incorrectly to two or more of the questions. Using this summarised score of mothers' knowledge about various methods of HIV transmission in MTCT, 76 (40\%) of the participants gave one correct response, $65(34 \%)$ gave two correct responses, and $50(26 \%)$ gave three correct responses.

The majority $(176,92 \%)$ of the HIV-positive mothers reported that even if provided with a free supply of IF, they would still prefer to exclusively breastfeed their infant, but 15 mothers (8\%) preferred to formula feed their infants.

Most mothers (150, 78\%) reported that their partners preferred them to EBF, but $30(16 \%)$ partners preferred the mother to formula feed, while $11(6 \%)$ mothers were not sure of the partner's preference. About half $(90,47 \%)$ of the mothers agreed that infant feeding practices were decided by family members, while the rest of the mothers embraced the advice of the health staff $(67,35 \%)$, self $(32,17 \%)$ and spouse $(2,1 \%)$, respectively. More than half of the mothers (152, 79\%) felt that EBF was the best IFO, while the rest of the mothers preferred other IFO.

Most of the mothers were not adherent to their choice of feeding. The study revealed that more than three-quarters $(150,78 \%)$ introduced other feeds apart from breast milk at about 5-6 months, while 26 (14\%) EBF for more than 6 months, and $15(8 \%)$ introduced other feeds earlier.

Most of the mothers (156, 82\%) did not experience any challenges with EBF, while $11(6 \%)$ claimed to not have enough breast milk, 10 (5\%) had either cracked or sore nipples or were ill and $4(2 \%)$ experienced pressure from relatives or friends to give water, formula or solid food to their infants.

Mothers indicated that family pressure and concerns that breast milk would not be enough for their infant were the main reasons for using IF or MF before 6 months. Of the 15 mothers who EFF their infant, 14 (93\%) did so because of the worry of HIV transmission through breastfeeding, and $1(6 \%)$ was too ill with a breast problem. Of these formula feeding mothers, $10(67 \%)$ used piped or tap water for their IF preparation, and $5(33 \%)$ used water from a closed well. All mothers who agreed to formula feed indicated that the water 
was boiled before use. More than three-quarters (160, 96\%) will prefer to EBF if provided with IF.

There was a statistically significant relationship between the mother's age $(p<0.001)$ and knowledge of methods of reduction of MTCT of HIV in infant feeding, with younger mothers aged 18-25 years being more knowledgeable. This did not however translate into a difference in EBF practices, with age not being associated with EBF at $4-5$ months $(p=0.06)$.

The association between perception of the sufficiency of EBF in the first 6 months and mother's age $(p<0.08)$ and mother's education $(p=0.29)$ was not significant. The association between mothers' age and their desire to exclusively breastfeed their infants for the first 4-5 months was not statistically significant $(p=0.06)$.

Knowledge about various feeding options and the level of satisfaction with the level of information provided during the programme was not statistically significant at $p=0.68$, but the knowledge acquired about the various IFs compared with the time this information was given during this programme was statistically significant $(p<0.0001)$.

Mothers who received information, education and counselling on IFO early during pregnancy were more likely to exclusively breastfeed as compared to mothers who received IEC late in their pregnancy or postnatally $(p=0.01)$. Mothers' satisfaction with the IEC provided during the PMTCT programme was positively associated with EBF of infants $(p=0.006)$.

\section{Discussion}

This study investigated infant feeding KAP of HIV-positive mothers at health clinics referring to Queen Mamohato Memorial hospital in Maseru, Lesotho. The high response rate and profile of mothers who participated in the study is typical of HIV-positive women in developing countries where MTCT of HIV is a public health challenge. ${ }^{11}$

The majority of the mothers in the study were aware of the benefits of EBF and preferred to exclusively breastfeed their infants, in agreement with their mothers-in-law's and family advice. This is aligned with the strong cultural value attached to breastfeeding in the society. ${ }^{24}$

Most of the HIV-positive mothers were mindful of the risk of transmitting HIV to their infants during pregnancy, and the risk of MTCT associated with MF. This is similar to findings in other studies in sub-Saharan Africa, such as north-west Ethiopia, where most (89.5\%) of the respondents had a good knowledge about EBF. 25

The basic ethical principle of informed choice requires that HIV-positive mothers are provided with adequate information about their IFOs in the framework of PMTCT of HIV. ${ }^{6}$ The Lesotho National PMTCT guideline recommends that all pregnant mothers be counselled on infant feeding in order to make choices. The majority of the mothers were satisfied with the level of counselling and education provided on IFOs at the health facilities.

Early provision of IEC during pregnancy was associated with higher rates of EBF among the mothers.

Many health workers at the facilities had received training in the PMTCT programme a year prior to the study. ${ }^{6}$ The training provided by the International Centre for AIDS Care and Treatment Programmes (ICAP) in collaboration with the Elizabeth Glaser Paediatric AIDS Foundation may have contributed to the IEC provided by health services. ${ }^{6}$

Most mothers were aware that they could transmit HIV to their infants through breastfeeding, but other modes of transmission of HIV were generally less well known. This compares well to findings from a study in Ogun State, Nigeria, which revealed that only $27 \%$ of respondents understood the transmission of HIV during infant feeding. ${ }^{24}$

However, it was observed that three-quarters of the HIVinfected mothers understood that they need to make a choice between EBF and EFF. This gap suggests that there is some room for improvement with respect to education and counselling on infant feeding.

This outcome suggests a need to intensify health education on EBF among the mothers, with more emphasis on the goal and objectives of safe infant feeding practices. There was also overwhelming evidence that not all the mothers felt that breast milk was sufficient for the first 6 months. This implies that the knowledge about the sufficiency of breast milk for the first 6 months among mothers in the context of HIV and AIDS is still limited.

The proportion of MF in this study was $10.5 \%$, which is lower than that reported by a study conducted in Ghana $(40 \%){ }_{1}^{17}$ but closer to that of the study conducted in northern Ethiopia $6.3 \% .{ }^{26}$ This outcome might be because of mothers providing 'socially acceptable' responses to the research assistants who were nurses in some of the health facilities. Cross-sectional studies, although valid and reliable measures of initiation and duration of breastfeeding, have been shown to overestimate EBF. ${ }^{12}$ Mothers may therefore not have accurately recalled specific instances of providing water, or dates of introducing solids, and also the grandparents are left to care for these infants while the mothers are at work, unfortunately these grandparents are not included in the PMTCT programme. Alternative appropriate methods for detailed studies of the dietary intake of infants less than 6 months which include the use of previous-day or seven-day recall periods. ${ }^{27}$

In order to assess the role of society members, mothers were asked about who influenced their choice of IFO and the source of information. The most common source of information regarding IFOs adhered to by the mothers was from their mothers-in-law, followed closely by the nurses at 
the health facilities. It is worth noting that the preferences of IFOs by mothers are those of the relatives despite the fact that the main source of information about IFO was from the health facilities.

This reinforces the difficulty women with HIV face in adhering to infant feeding in the face of the often overwhelming pressures that they face from their families. It supports other studies which found that parents of HIVpositive mothers and other key family members are very important in MTCT prevention programmes. ${ }^{28}$

Few of the mothers who did not breastfeed did so because they were worried about transmitting the virus to their infants. This is similar to other studies in India, where the majority of the mothers chose not to breastfeed for similar reasons. ${ }^{29}$

The pressure from relatives and friends to give water or adult foods to the infants has been attributed as the other challenges preventing HIV-positive mothers from exclusively breastfeeding their infant in the first 6 months. Therefore, there is a need for a multidimensional behavioural change strategy involving mothers and other family members. The finding that most participants felt that HIV-positive mothers are still experiencing discrimination in the community further reinforces the need for broader IEC and behavioural change strategies.

\section{Limitations}

Only HIV-positive mothers attending the Queen Mamohato three filter clinics located in three large districts in Maseru were included in the study, limiting the generalisability of the study to the rest of Lesotho or other countries.

The maternal self-reporting method used in this study is a valid and reliable method of measuring knowledge and attitudes, as well as initiation and duration of breastfeeding particularly for short-term recall. However, it may overestimate EBF and underestimate MF practices. The involvement of health workers as research assistants may also have contributed to participants providing more 'socially acceptable' responses, leading to an overestimation of the desirable IFOs.

Lastly, as not all infants were 6 months old at the time of the survey, infant feeding practices may not reflect the actual 6-month practice of the mother infant pairs.

\section{Recommendations}

The finding that some of the participants do not receive the recommended counselling on infant feeding underscores the need for the PMTCT programme in Lesotho. Although the Lesotho policy is aligned with international recommendations, the government needs to improve upon the present level of education among mothers and the communities so that they can make informed choices with respect to proper IFOs.
Further research is needed to understand the factors that affect women's infant feeding decision-making, particularly the role of partners and mothers-in-law.

\section{Conclusions}

HIV-positive mothers attending the PMTCT programme in Lesotho generally are knowledgeable and show a positive disposition to EBF their infants, with a clear understanding of the benefits of EBF.

Concerns about the sufficiency of EBF in the first 6 months was noted to be the major factor for mothers practising other forms of infant feeding. Therefore, the education and counselling concerning postnatal HIV transmission and safe IFOs should be adequate and clear.

The support of mothers-in-law or other key family members is an important factor in determining HIV-positive mothers' infant feeding choices. Strong efforts should therefore be made to involve key family members in PMTCT programmes.

In summary, this study found that some mothers do not understand the risks of not practising correct IFOs, and confirmed that breastfeeding is considered a cultural norm as has been reported in similar settings of sub-Saharan Africa. ${ }^{30}$ HIV-positive mothers in Lesotho and similar settings need to be supported by the health care system, family and community in initiating and practising EBF for their HIVexposed infants. Failure by policymakers to address these issues adequately will continue to lead to a gap between well-intended policies and programmes, and actual practices of HIV-positive mothers in Maseru, Lesotho.

\section{Acknowledgements}

Firstly, I wish to thank the Lord Almighty in Heaven through the Lord Jesus Christ for being with me and granting me the grace and strength throughout my studies. I am greatly indebted to Prof. Lilian Dudley, my supervisor, for her intelligent guidance, encouragement, support and most especially patience at every stage of this study. Without her invaluable input, it would not have been possible for me to complete this dissertation. I would like to thank Dr Karen Prins, my hospital director, all members of the Department of Community Health, University of Stellenbosch, and the course coordinator for their assistance. Also Prof. R. Mash who always responded to my email at odd times during the peer review.

Finally, my special thanks go to my wife, who gave me a hand when I most needed it.

This research project is prepared in partial fulfilment of the requirements for the Master's of Science in Clinical Epidemiology degree at the Faculty of Medicine and Health Sciences, Stellenbosch University, Cape Town, South Africa. 


\section{Competing interests}

The authors declare that they have no financial or personal relationships that may have inappropriately influenced them in writing this article.

\section{Author's contributions}

S.O. conceptualised this study, facilitated data collection, and led the data analysis under the close supervision of my supervisor L.D. L.D. supervised the development of the research protocol, the data collection tools, the data analysis, and the drafting of the article, which included reviewing and contributing to the revision of the final manuscript.

\section{References}

1. UNAIDS. UNAIDS 2015 | AIDS by the numbers [homepage on the Internet]. [cited 2015 Mar 19]. Available from: www.unaids.org/sites/.../JC2571_AIDS_by_the_ numbers_en_1.pdf

2. Government of Lesotho. National Guidelines for HIV and AIDS care and Treatment 2014 Government of Lesotho [homepage on the Internet]. Maseru. [cited 2015 Jun 08]. Available from: www.emtct-iatt.org/.../National-ART-Guidelines Final_16-June-20142.pdf

3. Government of Lesotho. Guidelines to prevent mother to child transmission of HIV 5th edition [homepage on the Internet]. 2016. [cited 2016 Aug 08]. Available from: www.health.gov.ls/documents/Revised\%20PMTCT\%20GUIDELINES.pdf

4. Lesotho Health Data - 2015 Profile - Countdown to 2015 [homepage on the Internet]. [cited 2017 Jan 31]. Available from: http://www.countdown2015mnch. org/documents/2015Report/Lesotho_2015.pdf

5. Appolinaire T, Leopold B, Anthony I, et al. Prevention of mother to child transmission (PMTCT) in rural Lesotho: A cornerstone for reducing paediatric HIV/ AIDS in resource-limited settings. [cited 2017 Jan 31]. Available from: http://pdf usaid.gov/pdf_docs/Pnadx553.pdf

6. De Cock KM, Fowler MG, Mercier E, et al. Prevention of mother-to-child HIV transmission in resource-poor countries: Translating research into policy and practice. JAMA. 2000;283:1175-1182. https://doi.org/10.1001/jama.283.9.1175

7. Coutsoudis A, Dabis F, Fawzi W, et al. Late postnatal transmission of HIV-1 in breast-fed children: An individual patient data meta-analysis. J Infect Dis. 2004;189:2154-2166. https://doi.org/10.1086/420834

8. Kourtis AP, Lee FK, Abrams EJ, Jamieson DJ, Bulterys M. Mother-to-child transmission of HIV-1: Timing and implications for prevention. Lancet Infect Dis. 2006;6:726-732. https://doi.org/10.1016/S1473-3099(06)70629-6

9. WHO, UNICEF, UNAIDS, UNFPA. HIV and infant feeding. Update. Based on the technical consultation held on behalf of the Inter-agency Task Team (IATT) on Prevention of HIV Infection in Pregnant Women, Mothers and their Infants; 2006 Oct 25-27; Geneva, Switzerland; 2007.

10. WHO/UNICEF/UNAIDS. HIV and Infant Feeding: Guideline for decision make 1998:WHO/FRH/NUT/CHD/98.1 [homepage on the Internet]. [cited 2016 May 16]. Available from: http://whqlibdoc.who.int/publications/2007/97892 May 16]. Available

11. WHO. Country Cooperation Strategy at a glance [homepage on the Internet] 2013. [cited 2015 May 19]. Available from: http://www.who.int/countryfocus/ cooperation_strategy/ccsbrief_Iso_en.pdf

12. WHO. Indicators for assessing breastfeeding practices 1991 (WHO/CDD/ SER/91.14) [homepage on the Internet]. [cited 2017 Jan 31]. Available from http://www.who.int/nutrition/publications/iycf_indicators_for_peer_review.pdf

13. Ladzani R, Peltzer K, Mlambo MG, Phaweni K. Infant-feeding practices and associated factors of HIV-positive mothers at GertSibande, South Africa. Acta Paediatr. 2011;100(4):538-542. https://doi.org/10.1111/j.1651-2227.2010.02080.x
14. Wachira J, Otieno-Nyunya B, Ballidawa J, Braitstein P. Assessment of knowledge, attitudes and practices of infant feeding in the context of HIV: A case study from western Kenya. SAHARA J [serial online]. 2009 [cited 2015 May 19];6(3): 120-126; quiz 127-133. Available from: http://www.ncbi.nlm.nih.gov/pubmed/ 120-126; quir

15. Navubya D, Kakanwage A, Okirya A, et al. Evaluation of a community-based prevention of mother to child transmission (PMTCT) programme in a slum area of Kampala, Uganda: AIDS 2010 - XVIII International AIDS Conference: Abstract no. CDD0975. [cited 2016 May 19]. Available from: pdf.usaid.gov/pdf_docs/ Pnadx553.pdf

16. Suuk AL, Veloshnee G. Factors influencing the choices of infant feeding of HIV positive mothers in Southern Ghana: The role of counsellors, mothers, families and socio-economic status. J AIDS HIV Res. 2011;3(7):129-137. [cited 2016 May 19]. Available from: http://www.academicjournals.org/article/article1379 512157.

17. Yeo EA, Béquet L, Ekouévi DK, Krawinkel M. Attitudes towards exclusive breastfeeding and other infant feeding options--a study from Abidjan. Cote d'Ivoire J Trop Pediatr. 2005;51(4):223-226. https://doi.org/10.1093/tropej/fmi005

18. Ministry of Health and Social Welfare. Demographic and health survey [homepage on the Internet]. Lesotho: Ministry of Health and Social Welfare, Bureau of Statistics; 2009. [cited 2015 May 7]. Available from: www.measuredhs.com/pubs/ pdf/FR241/FR241.pdf

19. Chopra M, Rollins N. Infant feeding in the time of HIV: Rapid assessment of infant feeding policy and programmes in four African countries scaling up prevention of mother to child transmission programmes. Arch Dis Childhood [serial online]. 2007 [cited 2016 May 15];93:288-229. PubMed. 2008. www.ncbi.nlm.nih.gov/ pubmed/17686796

20. Ruowei L, Scanlon KS, Serdula MK. The validity and reliability of maternal recal of breastfeeding practice. Nutr Rev [serial online]. 2005 [cited 2017 Feb 10] 63(4):103-110. Available from: https://www.ncbi.nlm.nih.gov/pubmed/ 15869124

21. Government of Lesotho. Kingdom of Lesotho National Tuberculosis Programme Policy and Manual 2013 [homepage on the Internet]. p. 9. [cited 2015 May 16] Available from: http://www.who.int/hiv/guidline/lesotho_tb.pdf

22. Bhagavathula AS, Bandari DK, Elnour AA, et al. A cross sectional study: The knowledge, attitude, perception, misconception and views (KAPMV) of adult family members of people living with human immune virus-HIV acquired immune deficiency syndrome-AIDS (PLWHA). Springer Plus. 2015;4:769. https://doi.org/ 10.1186/s40064-015-1541-2.

23. Stata Corp. Stata Statistical Software: Release 13. College Station, TX: Stata Corp LP; 2013.

24. WHO. PMTCT strategic vision 2010-2015: Preventing mother-to-child transmission of HIV to reach the UNGASS and Millennium Development Goals [homepage on the Internet]. [cited 2016 Jun 13]. Available from: www.who.int/hiv/pub/mtct/ strategic_vision.pdf

25. Kruger M, Ndebele $P$, Horn L. Research ethics in Africa: A resource for research ethics committees [homepage on the Internet]. [cited 2016 Sept 19]. Available from: http://www.sun.ac.za/english/faculty/healthsciences/paediatrics-and-childfrom: http://www.sun.

26. Olaitan O. Knowledge of transmission patterns of HIV/Aids among students of tertiary institutions in Kwara State Nigeria [homepage on the Internet]. 1993. [cited 2016 Sept 30]. Available from: www.cefwa.net/compilation_for_ proceedings.pdf

27. McLaughlin, Olivia M. Breastfeeding and subsistence work: Connecting theory and experience. Hilltop Rev [serial online]. [cited 2016 Mar 25];8(1):9. Available from: http://scholarworks.wmich.edu/hilltopreview/vol8/iss1/9

28. Bill SC, Otieno N, Siika A, Rotich S. Infant feeding practices among infected women receiving prevention of mother-to-Child Transmission services at Kitale District Hospital/ Kenya. East Afr Med J [serial online]. 2008 [cited 2015 Jun 19];85(4). Available from: http://www.ajol.info/index.php/eamj/article/download/9639/ 31054

29. Nishi S, Sasi J, Ashwini SE, et al. Infant feeding practices of HIV-positive mothers in India. J Nutr. 2003;133(5):1326-1331.

30. Dagnachew M, Desalegn W, Mucheye G, Moges T. Infant feeding practice and associated factors of HIV positive mothers attending prevention of mother to child transmission and antiretroviral therapy clinics in Gondar Town health institutions, Northwest Ethiopia. BMC Public Health. 2012;12:240. https://doi.org/10.1186/ 1471-2458-12-240 


\section{Appendix 1: Questionnaire}

This question is purely for the purpose of this research. All information given will be treated as confidential and does not require names or identities of the informants. Kindly indicate with ' $X$ ' the most appropriate response (s) to the questions below.

Thank You.

\begin{tabular}{|l|}
\hline A) SOCIODEMOGRAPHIC CHARACTERISTICS \\
\hline \\
\hline Serial Number: \\
\hline \\
\hline Age of Mother: Sex of baby..... Baby date of birth................. \\
\hline Place of birth: \\
\hline
\end{tabular}

1. Age (as last birthday) in years: Age (years)

(a) 18-20

(c) $31-40$

(d) 41-49

2. Marital status:

(a) Married

(b) Single

(c) Divorced

(d) Separated

(e) Widowed

(f) Cohabit

3. How many babies have you given birth to? ( Parity)

\begin{tabular}{|l}
\hline (a) primipara (1) \\
\hline (b) Low parity (2-3) \\
\hline (c) High parity ( $\geq 4)$ \\
\hline
\end{tabular}

4. Religion:

(a) Christian

(b) Muslim

(c) Traditional

(d) Other (specify)

5. Education-level completed:

(a) None

(b) Primary school

(c) Secondary school

(d) Higher than secondary

(e) Unknown

6. Employment status

(a) Government employment

(b) Privately employed

(c) Self-employment

(d) Unemployed or full-time housewife

(e) Student

(f) Volunteer

7. Does your spouse know about your HIV status?

(a) Yes

(b) No

8. Has your baby been tested for HIV?

(a) Yes

(b) No

(c) If no, why was your baby not tested...?

9. If yes what is your baby's HIV status?

(a) Positive

(b) Negative

10. What are the methods by which HIV can be transmitted from mother to a child?

(a) During pregnancy

(b) During delivery

(c) During breastfeeding 
(d) Cannot be transmitted from mother-to-child

(e) Do not know

11. Did you ever take antiretroviral (ARV)?

a) Yes

b) No

12. If yes, when did you start ARVs?

(a) Never did

(b) Only once before delivery

(c) Have been on antiretroviral before and after pregnancy

(d) Started after delivery

(e) Started during pregnancy and continue after

13. Did your child ever take antiretroviral?

a) Yes

b) No

14. If yes, when was the ARVs started after delivery?

(a) Only once after delivery

(b) Started days after delivery

(c) Immediately after delivery and continued for weeks or months

(d) Continue throughout breastfeeding

(e) Never did

\section{B) KNOWLEDGE OF INFANT FEEDING OPTIONS}

15. How satisfied were you with the amount of education and counselling on infant feeding that you received?

(a) Completely satisfied

(b) Very satisfied

(c) Somewhat satisfied

(e) Somewhat dissatisfied

(f) Very dissatisfied

(g) Completely dissatisfied

16. When did you receive any information about infant feeding options during pregnancy in the antenata clinics (ANC)?

(a) Never received any information

(b) During pregnancy or immediately after delivery

(c) Few weeks after delivery

(d) Months after delivery

17. What are the various infant feeding options you know? * (more than one allowed)

(a) Cow's milk

(b) Infant formula only

(c) Surrogate mother only

(d) Breastfeeding only

(e) Heat treating express breast milk

(f) Other

18. What advice were you given in terms of infant feeding during your ANC by the nurses or the counsellor?

(a) To breastfeed only

(b) To formula feed only

(c) To give both breastfeeding and formula

(d) Counselled on both exclusive breastfeeding and exclusive formula feeding and asked to make a choice

(e) Other

19. How can you reduce the risk of HIV transmission through breastfeeding?

(a) Stop breastfeeding as soon as feasible in the first few months

(b) Avoid mixed feeding or given only breast milk or formula

(c) Heat treating milk

(e) Give antiretroviral to the mother and child

(f) Other (specify)

20. Which infant feeding option has the highest risk of HIV transmission?

(a) Exclusive breastfeeding

(b) Infant formula feed

(c) Mixed feeding (giving both breast milk and formula milk)

(d) Cow's milk

(e) Do not know

21. Do you know the benefit of exclusive breasffeeding (EBF)? 


\section{C) ATTITUDE ABOUT INFANT FEEDING OPTIONS}

22. Will you have breastfed even with free supply of infant formula?

(a) Yes

(b) No

(c) I do not know

23. Which feeding option would you most like to be able to use?

(a) Exclusive breastfeeding

(b) Infant formula feed

(c) Mixed feeding (giving both breast milk and formula milk)

(d) Cow's milk

(e) Do not know

24. Which feeding option does your partner feel you should use?

(a) Exclusive breastfeeding

(b) Infant formula feed

(c) Mixed feeding (giving both breast milk and formula milk)

(d) Cow's milk

(e) Do not know

25. Which feeding option do other family members feel is the best to use?

(a) Exclusive breastfeeding

(b) Infant formula feed

(c) Mixed feeding (giving both breast milk and formula milk)

(d) Cow's milk

(e) Do not know

26. Have you been told not to use any infant feeding options by family and friends?

(a) Yes

(b) No

27. Which options have you been told not to use?

(a) Exclusive breastfeeding

(b) Infant formula feed

(c) Mixed feeding (giving both breast milk and formula milk)

(d) Cow's milk

28. Who do you listen to most about infant feeding?
(a) Partner
(b) Mother
(c) Partners
(e) Family member
(f) Friends

(e) Nurse

(f) $\mathrm{CHW}$

29. Do you think breastfeeding alone is enough in the first 6 months for proper growth?
(a) Yes
(b) No
(c) I do not know

\section{D) INFANT FEEDING PRACTICES}

30. In the first 6 months what feeding options did you give to your child?

(participant can select more than one )

(a) Breastfeeding only (exclusive breastfeeding)

(b) Breastfeeding and water

(c) Formula feeding only

(d) Breastfeeding, formula feeding and water

(e) Heat-treated express milk

(f) Other

31. Who decided on the feeding option(s) that you chose for your baby?

(a) Spouse

(b) Self

(c) Family member

(d) Doctor or nurses

(e) Other

32. How long did you exclusively breastfeed (breast milk alone)?

(a) Less than 1 month

(b) 2-3 months

(c) 4-6 months

(d) Still breastfeeding

(e) Others 


\begin{tabular}{|c|c|}
\hline \multicolumn{2}{|l|}{ 33. At what age did you introduce other feeds apart from breast milk? } \\
\hline \multicolumn{2}{|l|}{ (a) From birth } \\
\hline \multicolumn{2}{|l|}{ (b) 1-2 months } \\
\hline \multicolumn{2}{|l|}{ (c) 3-4 months } \\
\hline \multicolumn{2}{|l|}{ (d) 5-6 months } \\
\hline \multicolumn{2}{|l|}{ (e) No other feeds in first 6 months } \\
\hline \multicolumn{2}{|l|}{ 34. If you gave breast milk and formula or water or other diets before 6 months give reason? } \\
\hline \multicolumn{2}{|l|}{ (a) Breast milk not enough } \\
\hline \multicolumn{2}{|l|}{ (b) Pressure from family or friends } \\
\hline \multicolumn{2}{|l|}{ (c) Cost of purchasing formula } \\
\hline \multicolumn{2}{|l|}{ (d) Ignorance of infant feeding option/HIV status } \\
\hline \multicolumn{2}{|l|}{ (e) Other } \\
\hline \multicolumn{2}{|l|}{ 35. How long did you give both breast and formula milk? } \\
\hline \multicolumn{2}{|l|}{ (a) Few days } \\
\hline \multicolumn{2}{|l|}{ (b) Less than 1 month -2 months } \\
\hline \multicolumn{2}{|l|}{ (d) Above 4 months } \\
\hline \multicolumn{2}{|l|}{ (e) Presently still given both } \\
\hline \multicolumn{2}{|l|}{ 36. What do you feel are the main problems or challenges with exclusive formula feeding? } \\
\hline \multicolumn{2}{|l|}{ (a) Expensive cost of purchasing formula milk } \\
\hline \multicolumn{2}{|l|}{ (b) No regular supply of formula milk } \\
\hline \multicolumn{2}{|l|}{ (c) Pressure from relatives or friends to give water and/or adult food } \\
\hline \multicolumn{2}{|l|}{ (d) Problem with working and feeding } \\
\hline (e) No challenges & \\
\hline 37. What do you feel are the main problems or challenges with exclusive breastfeeding? & \\
\hline (a) Breast milk not enough for child & \\
\hline (b) Pressure from relative or friends to give water or formula or adult diet & \\
\hline (c) Crack or sore nipple or ill mother & \\
\hline (d) No challenges & \\
\hline (e) Other & \\
\hline (a) Mother too ill or breast problem & \\
\hline (b) Worry about transmitting HIV & \\
\hline (c) Doctor or health provider advice & \\
\hline (d) Family advice & \\
\hline (e) Difficulty breastfeeding the infant & \\
\hline (f) Others & \\
\hline $\begin{array}{l}\text { 39. If using formula milk, in your living condition, what kind of water is used for the infant formula } \\
\text { preparation? }\end{array}$ & \\
\hline (a) Piped or tap water & \\
\hline (b) Spring flowing & \\
\hline (c) Close well & \\
\hline (d) River or pond & \\
\hline 40. If using formula milk what method of feeding is used? & \\
\hline (a) Feeding bottle & \\
\hline (b) Cup and spoon & \\
\hline (c) Both feeding bottle and cup or spoon & \\
\hline d) Other & \\
\hline $\begin{array}{l}\text { 41. Does discrimination against HIV-positive mothers in the community has any effect on your choice of } \\
\text { infant feeding options? }\end{array}$ & \\
\hline (a) Yes & \\
\hline (b) No & \\
\hline
\end{tabular}

THANK YOU FOR YOUR TIME. 